\title{
USO DA TERRA NA BACIA DO ARROIO DA RONDA (PONTA GROSSA/PR) E SUA INFLUÊNCIA NOS PROCESSOS GEOMORFOLÓGICOS NO PERÍODO DE 1980 A 2009
}

\author{
Land use in the Arroio da Ronda's basin (Ponta Grossa \\ City/PR) and its influence on geomorphological processes \\ occurring in the period from 1980 to 2009
}

\author{
Paula Mariele Meneguzzo ${ }^{1}$ \\ Edivaldo Lopes Thomaz ${ }^{2}$
}

\begin{abstract}
RESUMO
A presente pesquisa teve como objetivo principal avaliar o uso da terra na bacia do Arroio da Ronda (Ponta Grossa - PR) e sua influência nos processos geomorfológicos entre 1980 até 2009. Este intervalo foi dividido em três: 1980-1989, 1990-1999 e 2000-2009, sendo que em cada um foram identificados processos geomorfológicos, desenvolvidos em áreas urbanas ou rurais. Após a identificação dos processos, utilizou-se a equação de concentração de processos (CP), que resulta na concentração de processos $/ \mathrm{km}^{2}$. Assim, em cada intervalo temporal a equação foi aplicada, mostrando que à medida que houve o aumento da urbanização, o valor de CP cresceu, indicando que este fenômeno influencia sobremaneira os processos geomorfológicos. Na área rural ocorreu o aumento da CP de 1980 para 1990, mantendo-se estável em 2000.
\end{abstract}

Palavras-chave: bacia hidrográfica; uso da terra; processos geomorfológicos; Ponta Grossa.

\begin{abstract}
This research aimed at assessing the land use in the Arroio do Ronda's Basin (Ponta Grossa City / PR) and its influence on the geomorphological processes in the period 1980 to 2009. This time interval was divided into three periods: 1980-1989, 1990-1999 and 2000-2009, and in each of these periods geomorphological processes were identified. They are developed on rural and urban lands. After the processes identification, the concentration processes's equation (CP), which has resulted in concentration of processes $/ \mathrm{km}^{2}$ was used. Therefore, in each time interval the equation was applied, showing that as urbanization increased, the amount of CP got higher, indicating this phenomenon may influence considerably the geomorphological processes. At rural lands, there was an increase of $\mathrm{CP}$ from 1980 to 1990 and remaining stable in 2000.
\end{abstract}

Keywords: watershed; land use; geomorphological processes; Ponta Grossa City.

1 Este artigo é parte da dissertação: Evolução do uso da terra na bacia do Arroio da Ronda (Ponta Grossa - PR) e sua influência nos processos geomorfológicos, defendida junto ao Programa de Pós-Graduação em Geografia - Mestrado em Gestão do Território da Universidade Estadual de Ponta Grossa (UEPG). Bacharel e Licenciada em Geografia. Professora da Rede Estadual de Ensino do Estado do Paraná. E-mail: paulameneguzzo@hotmail.com

2 Orientador da referida dissertação. Doutor em Geografia (Geografia Física). Professor Adjunto - Departamento de Geografia Universidade Estadual do Centro-Oeste do Paraná - UNICENTRO. E-mail: ethomaz@brturbo.com.br 
MENEGUZZO, P. M.; THOMAZ, E. L. Uso da terra na Bacia do Arroio da Ronda...

\section{INTRODUÇÃO}

A bacia hidrográfica corresponde a uma "...área da superfície terrestre drenada por um rio principal e seus tributários sendo limitada pelos divisores de água" (BOTELHO, 2007, p. 269). Ela constitui-se em uma importante unidade de análise e de planejamento, sendo amplamente adotada como área de estudo em muitos trabalhos por consistir em um sistema aberto, entendendo-se sistema como um conjunto de fenômenos que se desenvolvem através de fluxos de matéria e energia, que causam dependência entre os fenômenos. Para compreender um sistema é necessário ter em mente que ele possui características próprias, não se reduzindo apenas a soma dos seus componentes (TRICART, 1977).

Considerando-se as bacias hidrográficas como sistemas, qualquer mudança em um dos seus componentes, poderá trazer consequências na dinâmica de toda a bacia. Assim, a vertente que constitui-se em um dos componentes da bacia hidrográfica também pode ser analisada sob a ótica sistêmica, pois ela se constitui em um sistema aberto, onde há entrada, circulação e saída de energia e matéria que se processa entre os seus constituintes, desencadeando assim, a atuação dos processos que modelam as paisagens. Além disso, há uma relação entre as vertentes e os canais fluviais, pois se ocorrer um processo geomorfológico na vertente, certamente o canal também sofrerá alguma mudança.

Os processos geomorfológicos fazem parte da dinâmica das paisagens, contudo, esses processos podem ter influência humana, no sentido de acelerar os já existentes ou mesmo desencadear novos processos. Com isso, a ocupação das encostas por parte das sociedades humanas pode trazer consigo inúmeras alterações na dinâmica natural, tanto nas vertentes quanto nos canais de drenagem. Dentre essas alterações, citase o desenvolvimento de processos geomorfológicos que tem como causas ações ligadas ao uso da terra, tanto em áreas urbanas quanto em áreas rurais. Os estudos abordando esses dois espaços são de suma importância pois podem ser utilizados no planejamento urbano ou rural, no entanto raramente este último é abordado, dada a dificuldade de transporte e de fontes de informações, por exemplo.

Casseti (1995) faz algumas considerações acerca do avanço da urbanização em vertentes, afirmando que, naquelas onde há cobertura vegetal, a tendência é armazenar água no lençol freático e assim alimentar o curso d'água. A partir do momento em que a vertente começa a ser ocupada, a primeira ação antrópica é a retirada da vegetação, deixando o solo exposto sobre- tudo à erosão hídrica, havendo aumento da carga sedimentar até que haja a selagem do horizonte superficial do solo. Quando a vertente encontra-se urbanizada, o escoamento superficial aumenta em consequência da impermeabilização, impedindo a infiltração da água. Assim, a descarga fluvial será controlada quase que exclusivamente pelo escoamento de superfície, respondendo pelas torrencialidades observadas nos grandes centros urbanos.

Tomando-se como base as assertivas anteriores, salienta-se que o uso e ocupação da terra muitas vezes podem significar pressão e impacto sobre os elementos naturais (SANTOS; SILVEIRA, 2004) alterando sua dinâmica. Com isso muitos processos geomorfológicos podem ser desencadeados, dentre eles: sulcos, ravinas, pipe associados a colapsos, escorregamentos, solapamentos de margens seguidos de desmoronamentos e inundações. Um dos processos mais comuns verificados na área estudada são os sulcos, entendidos aqui como “... erosões lineares abertas pelos pequenos filetes que se encaixam na superfície pela remoção de detritos ao longo do seu fluxo, na maior inclinação da vertente" (BIGARELLA, 2003, p. 924). As ravinas são outro tipo de feição erosiva do tipo linear, que apresentam pequenos deslizamentos nas suas paredes internas, causados pelo solapamento da sua base, devido ao escoamento das águas acarretando o aumento de suas dimensões (OLIVEIRA, 1994 apud RIDENTE JR, 2000).

Existem formas erosivas que surgem pela ação das águas subsuperficiais, neste caso, tem-se a erosão interna ou pipe. Esses são dutos subterrâneos com dimensões que atingem alguns centímetros ou metros (GUERRA, 2001). A origem desses se dá pelo transporte de materiais incoesos podendo também estar associado "... ao colapso de microestruturas de agregados do solo pelo fluxo da água subterrânea" (MEDEIROS, 2000, p. 7).

Além das erosões que ocorrem nas vertentes, estejam elas localizadas em áreas urbanas ou rurais, devem ser ressaltados também os movimentos de massa que atuam no modelado da paisagem e podem trazer perdas econômicas e sociais às pessoas que eventualmente estejam instaladas nas cercanias. O movimento de massa aqui abordado é o escorregamento, entendido como: "Descidas de solo ou das massas de rochas decompostas geralmente por efeito da gravidade" (GUERRA, A. T.; GUERRA, A. J. T. 2008, p. 244).

Outros processos geomorfológicos identificados na bacia analisada foram os solapamentos de margens com consequentes desmoronamentos, desenvolvidos quando a vazão dos cursos d'água é alta e as águas fluviais começam a erodir as margens dos canais, re- 
movendo grande quantidade de material. Este processo associa-se a outro, o desmoronamento, ou seja o "... deslocamento rápido de um bloco de terra, quando o solapamento criou um vazio na parte inferior da vertente" (CHRISTOFOLETTI, 1980, p. 29).

$\mathrm{O}$ aumento da vazão nos canais fluviais quando de intensos episódios chuvosos, aliados às alterações no regime hidrológico, afetam prejudicialmente populações que eventualmente residam nas planícies de inundação. As inundações ocorrem quando a descarga do rio torna-se elevada e excede a capacidade do canal, extravasando suas margens e alagando as planícies adjacentes (RICCOMINI; GIANNINI; MANCINI, 2001).
Na bacia do Arroio da Ronda (Ponta Grossa - PR) (FIGURA 1), a qual corresponde a área de estudo desse trabalho é comum a existência dos processos geomorfológicos tratados anteriormente, sendo encontrados tanto em áreas com uso urbano quanto rural. Destacase que, neste trabalho, essas áreas correspondem as classes de uso da terra abordadas, havendo variações na concentração de processos (CP) ao longo dos vinte e nove anos estudados, em ambas as áreas.

Diante disso, o objetivo deste trabalho é avaliar o uso da terra na bacia do Arroio da Ronda (Ponta Grossa - PR) e sua influência nos processos geomorfológicos entre os anos de 1980 até 2009.

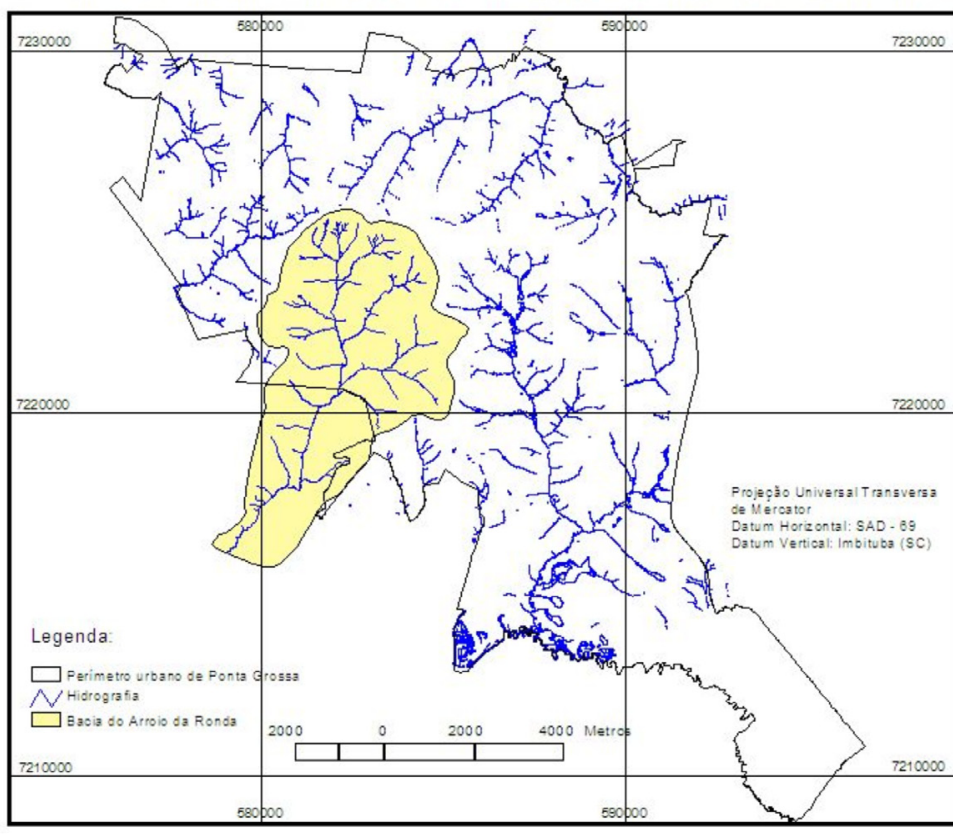

ESTADO DO PARANÁ COM DESTAQUE PARA O MUNICIPIO DE PONTA GROSSA

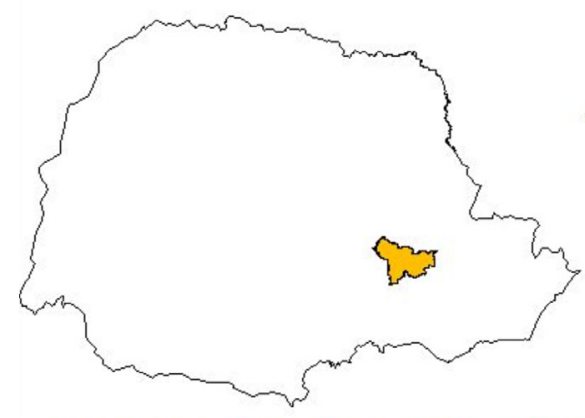

MUNICIPIO DE PONTA GROSSA E SUA ÁREA URBANA

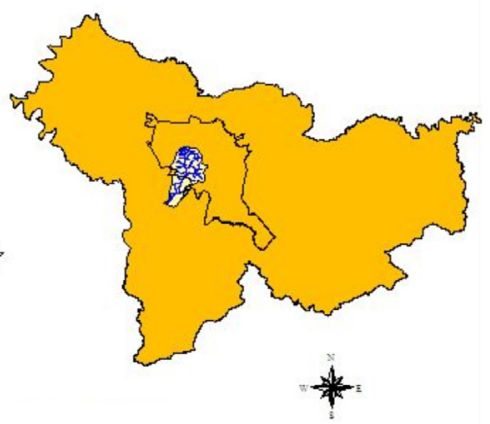

FIGURA 1 - LOCALIZAÇÃO DA BACIA DO ARROIO DA RONDA NO MUNICÍPIO E NA CIDADE DE PONTA GROSSA FONTE: IBGE (2004) Prefeitura Municipal de Ponta Grossa. Imagem: Ikonos (2004). Org: MENEGUZZO, P. M. 
MENEGUZZO, P. M.; THOMAZ, E. L. Uso da terra na Bacia do Arroio da Ronda...

\section{CARACTERIZAÇÃO DA BACIA DO ARROIO DA RONDA}

A bacia do Arroio da Ronda localiza-se na porção sudoeste da cidade de Ponta Grossa (PR) (Figura 1), seguindo na mesma direção até desaguar no Rio Tibagi. A bacia em questão possui uma área de $35,76 \mathrm{~km}^{2}$, sendo $24,03 \mathrm{~km}^{2}$ localizados no perímetro urbano de Ponta Gros$\mathrm{sa}^{3}$, enquanto $11,73 \mathrm{~km}^{2}$ correspondem a área rural.

O clima do município de Ponta Grossa, onde insere-se a bacia do Arroio da Ronda é do tipo Cfb (clima subtropical úmido mesotérmico). No intervalo temporal entre 1980 - 2004, constatou-se que, a temperatura média anual foi de $17,8^{\circ} \mathrm{C}$, oscilando entre $19,2^{\circ} \mathrm{C}$ e $17,2^{\circ} \mathrm{C}$, apresentando portanto uma variação de $2^{\circ} \mathrm{C}$. A maior média de temperatura foi registrada no ano de 2002 e a menor média no ano de 1989.

Em relação à precipitação, na série histórica de 1980-2004, o ano com maior precipitação registrada foi $1998 \mathrm{com} 2500 \mathrm{~mm}$. O segundo ano com maior precipitação foi $1983 \mathrm{com} 2250 \mathrm{~mm}$. O mês com maior precipitação foi janeiro com um total de aproximadamente $180 \mathrm{~mm}$, seguido do mês de dezembro com aproximadamente $170 \mathrm{~mm}$. Esses últimos dados são normais para a região, pois o período com maior quantidade de chuvas corresponde ao verão, entre os meses de dezembro e fevereiro. As chuvas que caem nesse período, geralmente durante a tarde, correspondem a eventos curtos, porém intensos, em consequência do calor elevado. Outros eventos chuvosos estão relacionados à entrada de massas de ar tropicais vindas do interior do continente e que estão carregadas de calor e chuvas (PMPG, 2006).

$\mathrm{Na}$ bacia estão presentes rochas sedimentares e ígneas pertencentes à Bacia Sedimentar do Paraná, como a Formação Ponta Grossa (folhelhos, folhelhos sílticos e siltitos), Grupo Itararé composto por arenitos finos a médios, argilitos, diamictitos e ritmitos, podendo se encontrar também, texturas areno-argilosas a arenosiltosas, intrusivas básicas correlatas à Formação Serra Geral, que estão intercaladas com as rochas sedimentares, principalmente sob a forma de soleiras e diques de diabásio (MELO; GODOY, 1997) e os sedimentos quaternários, presentes nas rampas colúvio-aluviais e nas planícies aluviais, caracterizados por camadas de materiais com granulometria diferenciada (argilas até areias) (MEDEIROS, 2000).

A declividade na bacia é bastante variada em consequência do controle estrutural existente. Nas proximidades das cabeceiras norte, há o predomínio de declividades acima de $20 \%$ e em alguns pontos $>30 \%$. Exceto nas encostas da margem direita do curso d'água principal, onde as declividades são maiores que $20 \%$, a partir do médio curso, seguindo em direção à foz, as declividades tendem a diminuir, situando-se nas faixas inferiores a $6 \%$ e de 6 a $12 \%$, onde as vertentes são mais suaves.

As vertentes são em sua maioria do tipo convexas, havendo também vertentes retilíneas, sobretudo localizadas na porção leste da bacia, mais precisamente na margem direita do Arroio do Padre (afluente da margem direita do Arroio da Ronda) e também na margem esquerda do canal principal do Arroio da Ronda. As vertentes côncavas são verificadas em maior quantidade na margem direita do curso d'água principal, próximo à foz.

As principais classes de solos observadas na bacia são os Latossolos Vermelhos geralmente com textura argilosa, porém, em alguns locais da bacia, foram observadas texturas areno-argilosas, pois os solos sofrem influência da rocha matriz arenosa pertencente ao Grupo Itararé. Quando derivados das rochas da Formação Ponta Grossa, os solos são dominantemente argilosos. Os Cambissolos também encontrados na área de estudo são constituídos por material mineral com horizonte $B$ incipiente, situado abaixo do horizonte $A$, sendo $A+B$ geralmente superior a $100 \mathrm{~cm}$, contudo podem situar-se entre 50 e $100 \mathrm{~cm}$ (SÁ, 2007). Em campo foram encontrados Cambissolos com profundidades em torno de $1,50 \mathrm{~m}$.

Já os Neossolos Litólicos são constituídos por material mineral ou por matéria orgânica, formando corpos delgados, que refletem a pouca ação dos processos pedogenéticos, sendo pouco evoluídos e bastante jovens (SÁ, 2007).

Os Gleissolos possuem constituição mineral, comumente desenvolvidos sobre sedimentos recentes, apresentando o horizonte A húmico e hístico, localizando-se sobretudo na faixa de transição entre os Cambissolos e os Gleissolos. Esses últimos são solos pouco evoluídos, ricos em matéria orgânica que provêm do acúmulo de restos vegetais em decomposição, situados em ambientes mal a muito mal drenados (SÁ, 2007).

A bacia do Arroio da Ronda passou a ser ocupada com mais expressão a partir da década de 1980, havendo ocupação de áreas onde anteriormente havia apenas sido traçada uma malha urbana situada nos interflúvios, onde a declividade predominante varia entre 12 e $20 \%$. Com o aumento da urbanização, muitos remanescentes

3 Esta quantificação foi feita tomando-se como base o novo perímetro urbano de Ponta Grossa proposto no Plano Diretor de 2006. 
MENEGUZZO, P. M.; THOMAZ, E. L. Uso da terra na Bacia do Arroio da Ronda...

de associação secundária de Floresta Ombrófila Mista situados nas nascentes foram destruídos, dando lugar às edificações.

No outro intervalo de tempo analisado 1990-1999, várias alterações de uso da terra ocorreram na bacia, como a redução das matas e campos localizados próximos aos cursos d'água no trecho superior, havendo a substituição da vegetação pela urbanização. Neste período, as faixas de vegetação, que já eram estreitas na década de 1980, diminuíram ainda mais, pois as ocupações próximas aos canais fluviais cresceram.

No trecho médio da bacia, as faixas de mata ciliar continuaram a existir, apesar das intensas mudanças de uso da terra ocorridas nesta porção, como a expansão dos reflorestamentos e consequente diminuição das áreas de campo.

Na década de 2000 consolidou-se a ocupação urbana nas cabeceiras a $\mathrm{N}$, seguindo a jusante, até a BR-376, onde anteriormente predominavam atividades agrícolas e/ou a vegetação campestre, típica da região de Ponta Grossa (PR). Nas proximidades da referida BR, haviam ainda capões de mata. Assim, a expansão da ocupação está ocorrendo principalmente nos afluentes da margem esquerda do Arroio da Ronda, porção onde existem bairros residenciais, voltados para a classes com maior poder aquisitivo.

\section{METODOLOGIA}

\section{INTERPRETAÇÃO DE IMAGENS DE SENSORES REMOTOS}

Para o desenvolvimento deste trabalho foram realizados vários procedimentos, como a fotointerpretação de fotografias aéreas de Ponta Grossa do ano de 1980 em escala 1:25.000, obtidas no Laboratório de Cartografia da UEPG e as fotos de 1995 em escala 1: 8.000 , as quais foram consultadas nas dependências da Prefeitura de Ponta Grossa. Foi verificada também, mas sem auxílio de nenhum instrumento óptico, a imagem do satélite IKONOS (2004), com resolução espacial de $1 \mathrm{~m}$ (um metro) cedida pelo Laboratório de Geoprocessamento da UEPG.

A utilização das imagens de sensores remotos, possibilitou a verificação do uso da terra na bacia, no caso das fotografias de 1980, 1995 e a imagem de 2004, e também a observação de alguns processos geomorfológicos ou evidências de suas atuações (fotos 1995 e imagem 2004). Como no "Projeto Erosão e Áreas de Risco no Espaço Urbano de Ponta Grossa (PR)" desen- volvido pela UEPG em parceria com o CNPq, já haviam sido identificados processos geomorfológicos ocorridos na cidade de Ponta Grossa fazendo uso das mesmas fotografias aéreas de 1995, os mapas produzidos por este projeto também foram utilizados, porém apesar disso, novo processo de fotointerpretação foi feito buscandose verificar nas fotos, mais processos geomorfológicos não detectados na interpretação anterior. No entanto, cabe ressaltar que alguns processos como os sulcos e os solapamentos de margens com consequentes desmoronamentos não puderam ser identificados nos materiais cartográficos em função da escala.

\section{TRABALHO DE CAMPO}

Outro procedimento adotado nesta pesquisa foram os trabalhos de campo, com o intuito de checar as diferentes classes de solos presentes na bacia, localizar novas evidências da atuação de processos geomorfológicos, bem como, verificar o estado atual daqueles identificados nas imagens de sensores remotos. A identificação dos processos em campo foi feita a partir das definições teóricas de cada um, bem como, dos conhecimentos prévios estabelecidos em trabalhos anteriores.

\section{PESQUISA EM JORNAIS}

Como o recorte temporal estabelecido nesta pesquisa é de vinte e nove anos, fez-se necessário também, utilizar como fonte de informações acerca dos processos geomorfológicos ocorridos em décadas passadas, os jornais da cidade de Ponta Grossa. Assim, foi consultado o Jornal da Manhã, pois este já existia em 1980 e não sofreu interrupções em suas publicações ao longo dos anos. Todas as reportagens encontradas traziam fotos dos processos ocorridos, possibilitando assim sua identificação. Como nas reportagens é comum serem citados os bairros, as ruas e os cruzamentos de ruas onde existem (existiam) processos, foi possível localizar espacialmente na área de estudo os processos geomorfológicos, os quais foram posteriormente mapeados conforme o período em que ocorreram, respeitando a legenda estabelecida para representá-los. Esta foi extraída do "Projeto Erosão e Áreas de Risco no Espaço Urbano de Ponta Grossa - PR", sofrendo adaptações como a inclusão de simbologia para as ravinas, solapamentos de margens com consequentes desmoronamentos e áreas inundadas. 


\section{ENTREVISTAS}

Ainda em decorrência do recorte temporal deste trabalho, optou-se por entrevistar antigos moradores da área de estudo, visando obter informações acerca dos processos geomorfológicos. Assim muitos processos já ocorridos foram informados por moradores, os quais sabiam indicar a sua localização. A identificação dos processos por parte dos moradores foi possível através da verificação dos processos in loco, pois, a maioria dos processos ocorridos em décadas passadas, ainda ocorrem nos mesmos locais. Assim, observando os processos ocorridos, os moradores sabiam indicar onde haviam mais feições semelhantes.

\section{MAPEAMENTO TEMÁTICO}

A partir do levantamento de informações, passou-se à elaboração dos mapas de processos geomorfológicos da bacia do Arroio da Ronda. Para tanto, foi necessário definir primeiramente três recortes temporais os quais permitiram melhor analisar o uso da terra, bem como, o aumento no número de processos em cada intervalo. Assim, foram definidos os seguintes intervalos: 1980-1989, 1990-1999 e 2000-2009. Seguindo esses, foram confeccionados três mapas de processos geomorfológicos, um para cada intervalo temporal, constando também dois grandes grupos de classes de uso da terra: urbano e rural ${ }^{4}$.

Para a produção dos três mapas foi utilizado o software Auto CAD 2006, que permite a entrada de dados vetoriais e georreferenciados, possibilitando desenhar facilmente a forma representativa de cada processo, uma vez que este é um software específico para desenho.

\section{AVALIAÇÃO DO USO DA TERRA NA BACIA DO ARROIO DA RONDA}

A última etapa realizada cujo intuito era avaliar o uso da terra na bacia do Arroio da Ronda e sua influência nos processos geomorfológicos, buscou apoio na metodologia de concentração de boçorocas (CB) (EQUAÇÃO 1) proposta por Ponçano, Kertzman e Salomão (1989). No entanto, a referida metodologia, sofreu algumas adaptações para ser aplicada na área de estudo, dentre elas a mudança na nomenclatura, a qual foi aqui denominada de concentração de processos (CP).

Na metodologia original, a equação CB foi aplicada somente para as ravinas profundas e as boçorocas, mas, neste trabalho ela foi utilizada para calcular a concentração de processos como um todo, ou seja, não foi feita distinção entre processos para aplicá-los na equação. Assim foram somados todos os processos identificados (escorregamentos, sulcos, ravinas, pipe associados a colapsos, solapamentos de margens com consequentes desmoronamentos e inundações) em cada intervalo temporal, e os totais foram então introduzidos na equação (EQUAÇÃO 2).

Ainda com relação à equação $\mathrm{CP}$, optou-se por não multiplicar o valor obtido por 100, resultando, portanto, em um número não inteiro seguido de duas casas decimais.

$$
\mathrm{CB}=\frac{\mathrm{N}}{\mathrm{A}} \times 100
$$

Onde :

$\mathrm{N}$ é o número de boçorocas pelo fator área;

A é a área expressa ${\mathrm{em} \mathrm{km}^{2}}^{2}$

Multiplica-se por 100 para a produção de um número de fácil leitura, representativo da média de boçorocas por $100 \mathrm{~km}^{2}$

Equação 1 - Concentração de boçorocas e ravinas profundas (CB)

$$
\mathrm{CP}=\frac{\mathrm{N}}{\mathrm{A}}
$$

Onde :

$\mathrm{N}$ é o número de processos pelo fator área;

A é a área expressa em $\mathrm{km}^{2}$

\section{Equação 2 - Concentração de processos (CP)}

A equação CP foi aplicada em cada um dos três intervalos temporais trabalhados, permitindo conhecer a concentração de processos nas áreas urbanas e rurais, bem como em toda a bacia.

4 Como foram trabalhados três períodos diferentes (1980, 1990 e 2000) foi preciso consultar o perímetro urbano vigente em cada ano, pois este foi alterado com o passar do tempo em virtude da expansão urbana. Para isso foi utilizado o limite estabelecido pelo projeto "Geoprocessamento aplicado ao mapeamento e análise da evolução da ocupação e uso da terra na cidade de Ponta Grossa (PR)", que delimitou a área urbanizada em 1980, não havendo o limite legal do perímetro urbano em virtude da dificuldade em se conseguir localizar espacialmente os limites impostos pela lei. Para os outros anos os limites do espaço urbano estão disponíveis em meio digital. 
MENEGUZZO, P. M.; THOMAZ, E. L. Uso da terra na Bacia do Arroio da Ronda...

\section{RESULTADOS E DISCUSSÃO}

Os primeiros dados incluídos na Equação 2 (CP), foram referentes a concentração de processos em toda a bacia, em cada um dos intervalos de tempo (QUADRO 1).

Iniciando a aplicação da equação pelo intervalo de 1980-1989, foram incluídos nela os seguintes dados: total de processos identificados na bacia do Arroio da Ronda $(\mathrm{N})$ que é igual a 34 e a área total da bacia 35,76 $\mathrm{km}^{2}$. O resultado obtido foi uma CP de 0,95 processos/ $\mathrm{km}^{2}$.

$$
\mathrm{CP}=\frac{34}{35,76 \mathrm{~km}^{2}}=0,95 / \mathrm{km}^{2}
$$

Esse intervalo apresentou a menor concentração de processos quando comparado aos demais, pois os valores cresceram nos intervalos posteriores, de modo que na década de $1990, \mathrm{CP}$ é igual a $1,42 / \mathrm{km}^{2}$ e na década posterior, igual a $1,28 / \mathrm{km}^{2}$ (QUADRO 1).

Quando se compara o uso da terra urbana com a área rural, nos três intervalos, os números apontam que também houve um aumento da $\mathrm{CP}$ em relação a 1980-1989.

A área urbanizada na bacia em 1980 (FIGURA 2) era de $13,27 \mathrm{~km}^{2}$ e a área rural de $22,49 \mathrm{~km}^{2}$. Nessa época, havia uma nítida transição entre a área urbanizada e a área rural, pois existiam inúmeros terrenos vazios, apenas com projetos de loteamentos e também áreas de campo, entre a área urbanizada e a área rural. Sendo assim, apesar da área urbanizada apresentar um tamanho menor que a área rural, foi na primeira que ocorreu a maior concentração de processos, ou seja, 1,13 processos $/ \mathrm{km}^{2}$, enquanto na área rural a concentração foi de 0,84 processos $/ \mathrm{km}^{2}$.

\begin{tabular}{|c|c|c|c|c|c|c|c|c|}
\hline $\mathbf{I T}^{1}$ & $\mathbf{T p}^{2}$ & $\mathbf{C P} \mathbf{b a c i a}^{3}$ & $\mathbf{P u}^{4}$ & $\mathbf{P r}^{5}$ & $\mathbf{A u}^{6}\left(\mathbf{k m}^{2}\right)$ & $\left.\mathbf{A r}^{7} \mathbf{k m}^{2}\right)$ & $\mathbf{C P}^{8}$ urbano & $\mathbf{C P}^{9} \mathbf{r u r a l}$ \\
\hline $1980-1989$ & 34 & $0,95 / \mathrm{km}^{2}$ & 15 & 19 & 13,27 & 22,49 & $1,13 / \mathrm{km}^{2}$ & $0,84 / \mathrm{km}^{2}$ \\
\hline $1990-1999$ & 51 & $1,42 / \mathrm{km}^{2}$ & 43 & 8 & 24,75 & 11,01 & $1,73 / \mathrm{km}^{2}$ & $0,72 / \mathrm{km}^{2}$ \\
\hline $2000-2009$ & 46 & $1,28 / \mathrm{km}^{2}$ & 38 & 8 & 24,75 & 11,01 & $1,53 / \mathrm{km}^{2}$ & $0,72 / \mathrm{km}^{2}$ \\
\hline
\end{tabular}

QUADRO 1 - CONCENTRAÇÃO DE PROCESSOS GEOMORFOLÓGICOS NA BACIA DO ARROIO DA RONDA E SUA DISTRIBUIÇÃO NA ÁREA URBANA E RURAL

NOTA: $\mathrm{IT}^{1}=$ intervalo temporal; $\mathrm{Tp}^{2}=$ total de processos na bacia; $\mathrm{CP}$ bacia ${ }^{3}=$ concentração de processos na bacia; $\mathrm{Pu}^{4}=\mathrm{Processos}$ na área urbana; $\mathrm{Pr}^{5}=$ Processos na área rural; $\mathrm{Au}^{6}=$ Área urbana; $\mathrm{Ar}^{7}=$ Área rural; $\mathrm{CP}^{8}$ urbano $=$ Concentração de processos no urbano; $\mathrm{CP}^{9}$ rural $=$ concentração de processos no rural

Apesar de concentrar no espaço rural o maior número de processos, este era maior que a área urbanizada, apresentando, portanto, uma concentração de processos menor. Os processos identificados entre 1980-1989 na área rural eram somente pipe associados a colapsos, ocorridos dominantemente em classes de uso da terra que caracterizam o meio rural, ou seja, cultivo, reflorestamento, ou ainda vegetação campestre.

No espaço urbano não foram identificados pipe nem colapsos, somente escorregamentos, sulcos e inundações. Percebe-se, portanto, que alguns processos ocorreram dominantemente em espaço urbano e outros prevaleceram no espaço rural, mostrando que as formas de uso da terra interferem sobremaneira nos processos, como pôde ser constatado comparando-se a concentração de processos entre os três intervalos, onde o valor $\mathrm{CP}$ só aumentou, se comparado com a década de 1980.
Além disso, é nítida a diferenciação existente entre a litologia, relevo, declividade e solos entre a área urbanizada e a área rural. No primeiro espaço, as declividades são mais acentuadas, sendo controladas pela litologia (soleiras de diabásio) e estruturas geológicas presentes (falhas encobertas e fraturas). As características citadas referentes à área urbana, aliadas a presença de solos menos evoluídos (Neossolos), eventos chuvosos atípicos para o clima da região e a estação da região, como aconteceu em 1983, ano em que o fenômeno El Niño, estava em ação, juntamente com a ocupação desses terrenos culminou em processos geomorfológicos, que algumas vezes foram catastróficos, havendo até mesmo a perda de vidas humanas, quando da ocorrência de escorregamentos.

Outros processos encontrados somente nas cidades foram os sulcos e as ravinas. Contudo, não se descarta a possibilidade de sua existência na área rural 
MENEGUZZO, P. M.; THOMAZ, E. L. Uso da terra na Bacia do Arroio da Ronda...

neste período, porém, nas poucas entrevistas feitas com moradores residentes neste espaço, não foram citadas a ocorrência de erosões lineares no passado nem na atualidade. Assim, eles apareceram apenas na área urbanizada, como resultado do ineficaz planejamento urbano, que se juntou à presença dos solos com maior teor de silte e areia, herdados do Grupo Itararé. Sola- pamentos de margens não foram identificados neste período, porém, podem ter ocorrido, mas não foram citados nas entrevistas, nem noticiados nos jornais, sendo tecnicamente inviável identificá-los nas fotografias aéreas de 1980 em virtude da escala (1:25.000). Destaca-se também que as erosões laminares não foram abordadas pelo mesmo motivo.

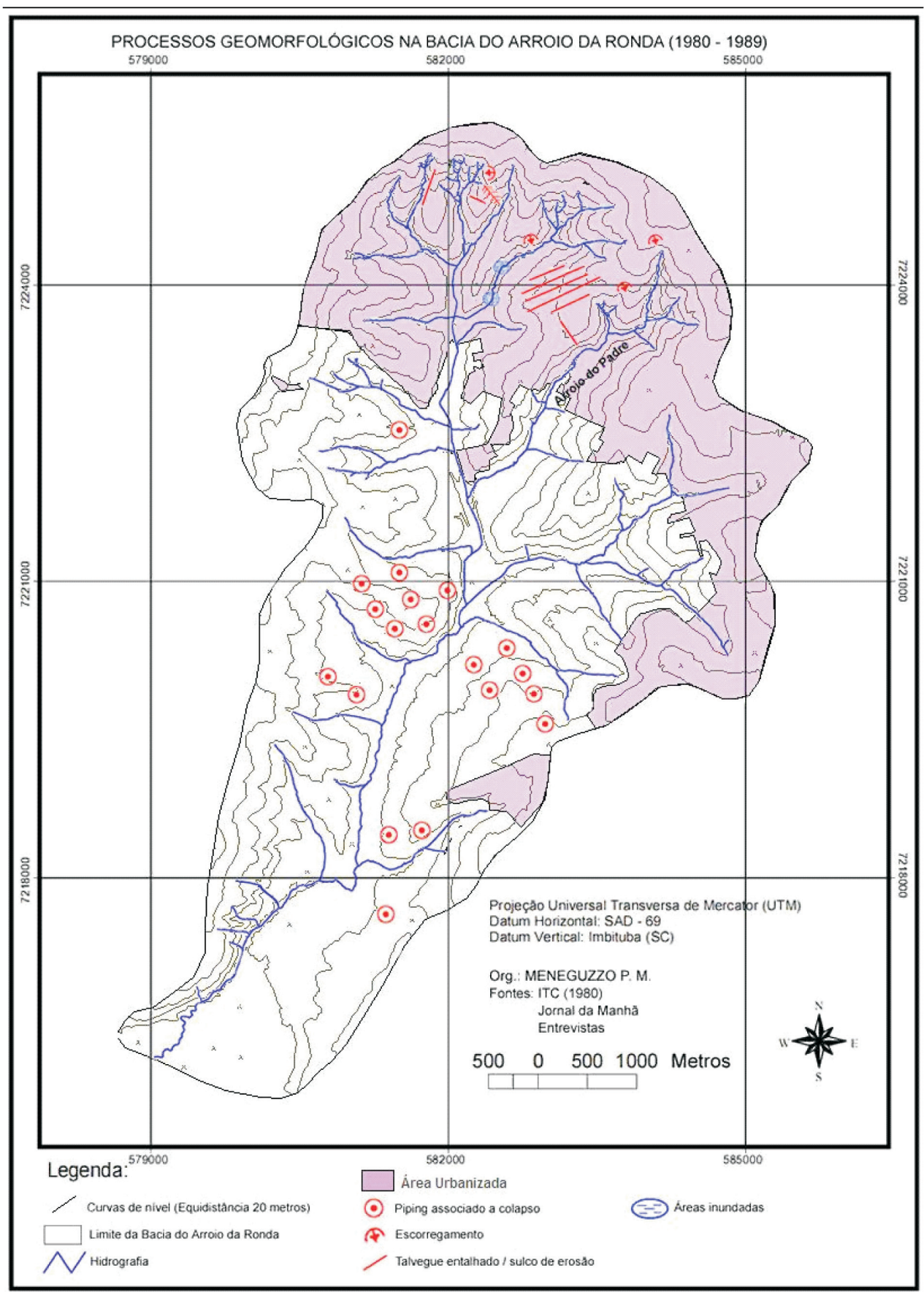

FIGURA 2 - MAPA DE PROCESSOS GEOMORFOLÓGICOS IDENTIFICADOS NA BACIA DO ARROIO DA RONDA ENTRE 1980-1989 
Chegando a década de 1990, sucedeu-se o aumento no número de processos, passando de 34 na década anterior para 51 no período considerado. Além do aumento no número de processos, na década de 1990 houve a ampliação do perímetro urbano de Ponta Grossa (FIGURA 3). A área urbana da bacia, passou para $24,75 \mathrm{~km}^{2}$ e o espaço rural totalizava $11,01 \mathrm{~km}^{2}$. De posse dessas informações, aplicou-se novamente a equação e obteve-se uma concentração de processos na bacia igual a 1,42 processos $/ \mathrm{km}^{2}$, sendo que a maior concentração novamente foi no espaço urbano com 1,73 processos $/ \mathrm{km}^{2}$ contra $0,72 / \mathrm{km}^{2}$ no rural.

Dessa vez, o número de processos no espaço urbano ultrapassou o número de processos na área rural e justificam o valor de CP. Sendo assim, no espaço urbano 43 processos foram identificados e no rural, 8 . Esses são os mesmos existentes na década passada, porém com a expansão da área considerada urbana, alguns passaram a estar contidos nela. Embora haja um número elevado de processos na década de 1990, as consequências dos mesmos, não foram tão desastrosas quanto às de 1980, pois nenhuma morte foi registrada, somente perdas materiais e pequenos ferimentos em algumas pessoas.

O período de 1990 caracterizou-se ainda por uma expansão urbana mais acentuada, com maior concentração de pessoas residindo em Ponta Grossa, pois em 1980 tinha-se um total de 171.818 pessoas, em 1991, 219.555, em 2000, 266.552 (LÖWEN-SAHR, 2001) e a estimativa para 2007 era de 306.351 (IBGE, 2007). Quanto maior o número de pessoas, maior é a necessidade de se extrair recursos naturais, bem como maior é a procura por áreas para moradia. Muitos recém-chegados sem recursos financeiros, acabaram por residir em locais inadequados, como margens de cursos d'água e encostas com declividades acentuadas, podendo desencadear ou acelerar a ocorrência dos processos.

Nas análises das fotografias aéreas de 1980 e de 1995, foi perceptível a ocupação de encostas com declividades acima de $20 \%$. Outras alterações de uso da terra foram observadas na bacia nesse período, em comparação com a década anterior, como a redução das matas e campos, os quais foram substituídos pela urbanização, reflorestamento e cultivo.

Neste período, as faixas de mata ciliar, que já eram estreitas em 1980, diminuíram ainda mais, pois as ocupações próximas aos canais fluviais cresceram, aumentando, também, o número de inundações registradas: duas na década de 1980 e quatro em 1990. Isso pode ser explicado pela ocupação das planícies aluviais, por parte de grupos de pessoas com baixo poder aquisitivo.

Através do levantamento de bibliografia, pôde-se perceber que, a partir da metade da década de 1990 trabalhos técnicos começaram a ser produzidos (MELO; GODOY, 1997), e pequenas ações paliativas foram tomadas pela PMPG, como a remoção das famílias residentes em áreas que de acordo com a Prefeitura, seriam de alto risco.

No intervalo entre 2000-2009 foram identificados 46 processos geomorfológicos na bacia. Isso mostra que os processos aumentaram se comparados com a década de 1980, e diminuíram se comparados com a década de 1990.

É possível fazer uma melhor comparação entre as décadas de 1990 e 2000, pois, nelas, o perímetro urbano de Ponta Grossa sofreu pequenas alterações, as quais não se situavam próximas da bacia do Arroio da Ronda (FIGURA 4). Sendo assim, a área urbana da bacia em 1990 e em 2000 foi a mesma, ou seja, 24,75 $\mathrm{km}^{2}$ e $11,01 \mathrm{~km}^{2}$ de área rural.

Aplicando-se a equação 2 (CP), o valor obtido para a década de 2000 na bacia foi de 1,28 processos/ $\mathrm{km}^{2}$, sendo a concentração na área urbana de 1,43 processos $/ \mathrm{km}^{2}$, pouco menor que em 1990. Já a concentração no rural foi a mesma: 0,72 processos $/ \mathrm{km}^{2}$. Sendo assim, na área rural nas décadas de 1980, 1990 e 2000 os processos predominantes foram os pipe associados a colapsos. Não se pode aqui discutir acerca da evolução destes, pois não dispomos de dados dos mesmos em décadas passadas, porém, nas observações feitas em campo, todos os pipe visitados apresentavam sinais de evolução, como blocos de solos recentemente movimentados e circulação de água em muitos dutos. 


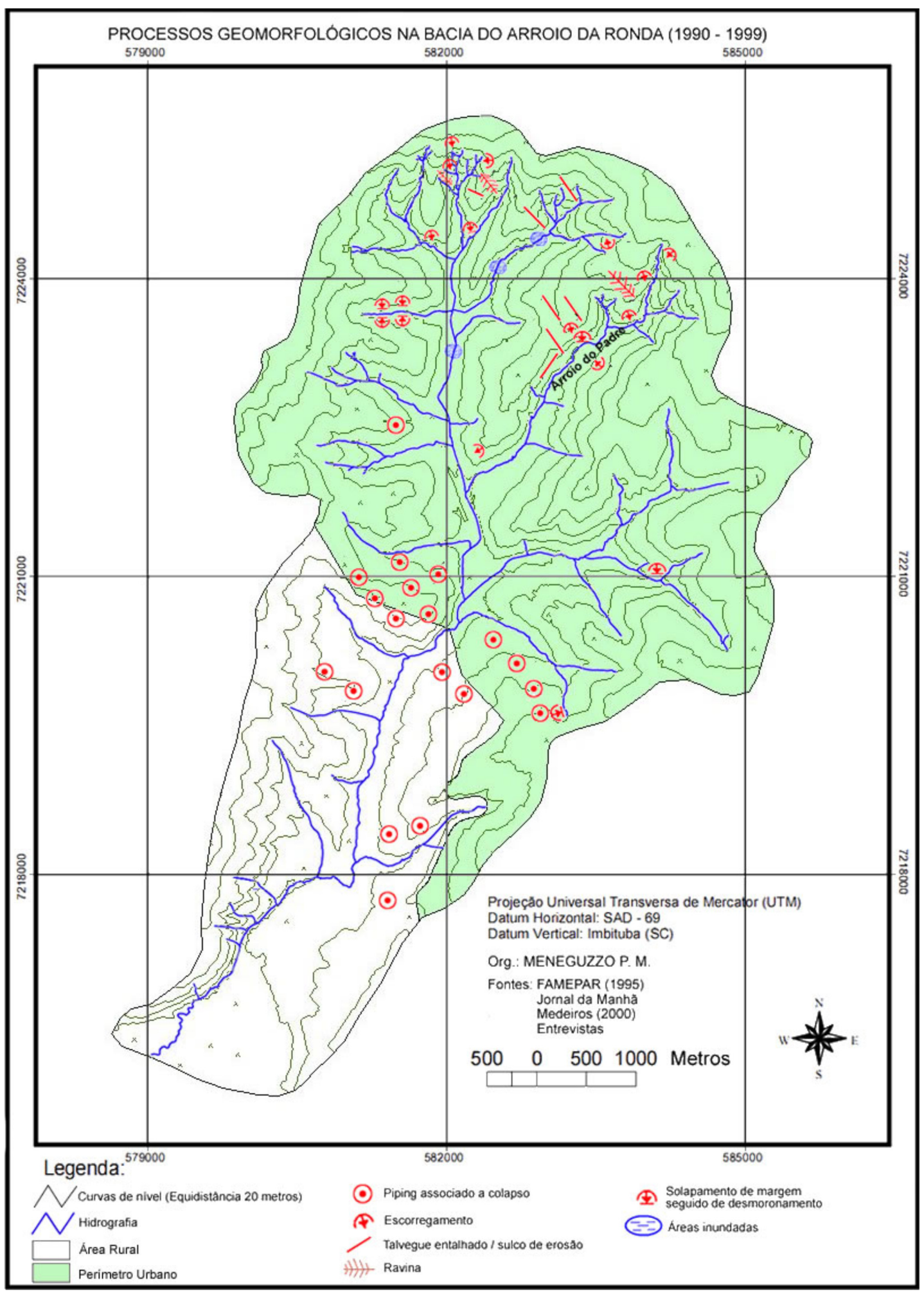

FIGURA 3 - MAPA DE PROCESSOS GEOMORFOLÓGICOS IDENTIFICADOS NA BACIA DO ARROIO DA RONDA ENTRE $1990-1999$ 


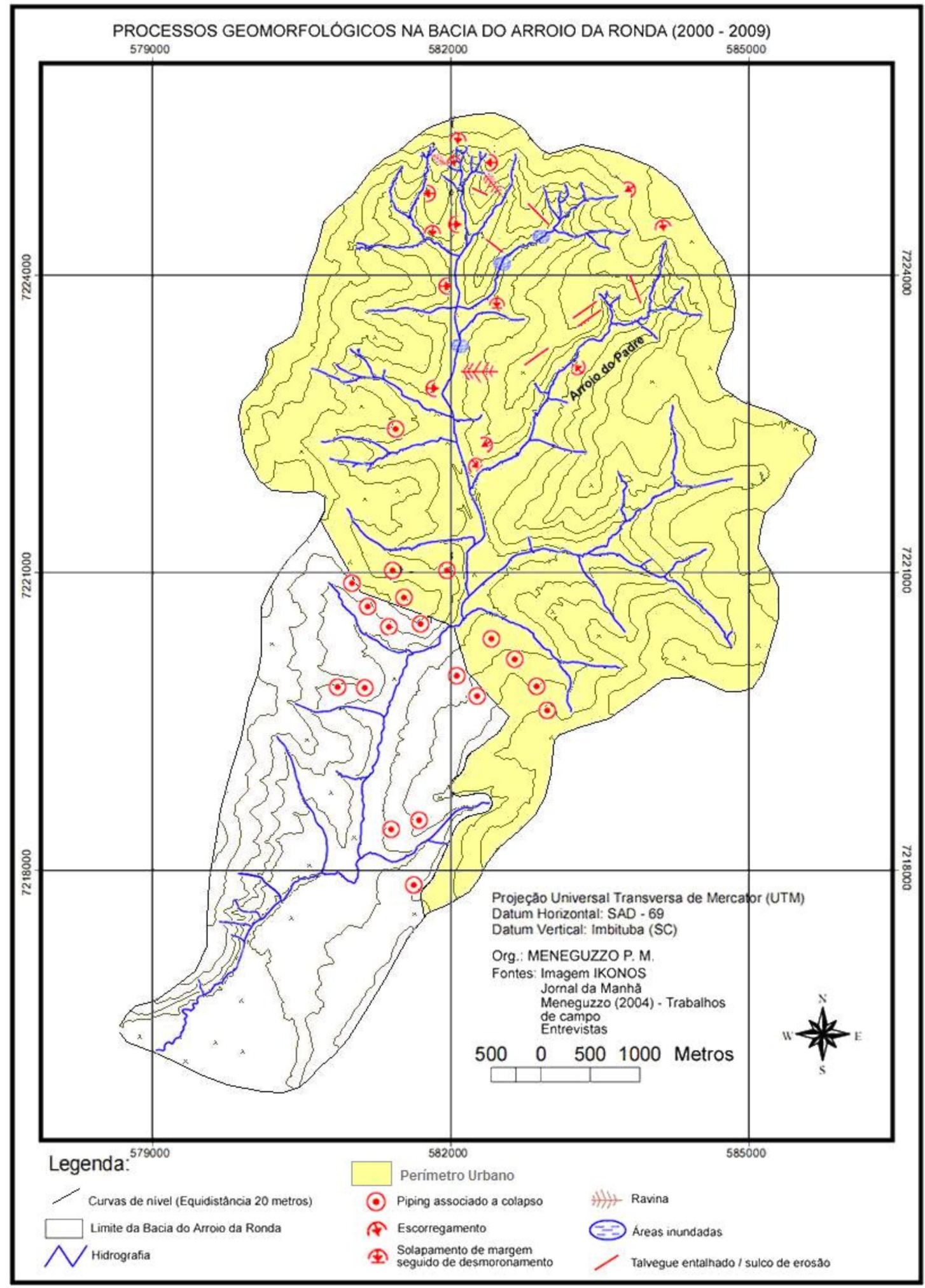

FIGURA 4 - MAPA DE PROCESSOS GEOMORFOLÓGICOS IDENTIFICADOS NA BACIA DO ARROIO DA RONDA ENTRE 2000-2009 
MENEGUZZO, P. M.; THOMAZ, E. L. Uso da terra na Bacia do Arroio da Ronda...

\section{CONCLUSÃO}

A bacia do Arroio da Ronda durante o intervalo de tempo analisado que totalizou 29 anos, apresentou mudanças nas formas de uso da terra, indicando um uso mais intenso da bacia, assim como, maior exposição dos solos a processos geomorfológicos.

Nos anos analisados houve o aumento das áreas urbanizadas e também o aumento da concentração de processos, pois na década de 1980 o valor da CP era 0,95/km², em 1990 atingiu 1,42/km² e em 2000 passou a ser de $1,28 / \mathrm{km}^{2}$. Essas informações indicam que as mudanças nas formas de uso da terra favoreceram o aumento dos processos geomorfológicos. Além disso, a CP também cresceu no perímetro urbano, se comparada com 1980, passando de $1,13 / \mathrm{km}^{2}$ para $1,73 / \mathrm{km}^{2}$ e $1,53 /$ $\mathrm{km}^{2}$. Na área rural houve o aumento da CP de 1980 para 1990, mantendo-se estável em 2000.

A partir dos mapas de uso da terra elaborados, algumas constatações foram produzidas referentes à evolução do uso da terra. No que se refere às áreas urbanas, as frentes de expansão ocorreram nas porções S, NW, W e SE, continuando sobretudo nos divisores mais planos, porém terrenos com maior declividade também passaram a ser ocupados gradativamente, os quais situam-se nas proximidades do centro da cidade de Ponta Grossa.

Nas áreas rurais pôde-se verificar algumas condições peculiares. Nas áreas onde ocorre o cultivo temporário, as declividades são mais suavizadas e práticas agrícolas que visam conservar e proteger o solo de processos geomorfológicos são realizadas. Assim, essa combinação contribui para que, em tais áreas não sejam encontradas erosões do tipo linear. Nesta área os processos identificados foram somente os pipe associados a colapsos.

\section{REFERÊNCIAS}

BIGARELLA, J. J. Estruturas e origens das paisagens tropicais e subtropicais: processos erosivos, vertentes, movimentos de massa, atividade endógena, superfície de erosão, compartimentação do relevo, depósitos correlativos e ambientes fluviais. Florianópolis: Ed. UFSC, 2003. v. 3. p. 1436.

BOTELHO, R. G. M. Planejamento Ambiental em Microbacia Hidrográfica. In: GUERRA, A. J. T.; SILVA, A. S. da; BOTELHO, R. G. M. Erosão e Conservação dos Solos. Rio de Janeiro: Bertrand Brasil, 2007. p. 269-300.

CASSETI, V. Ambiente e apropriação do relevo. 2. ed. São Paulo: Contexto, 1995. 147 p.
Já nas áreas urbanizadas os processos identificados são mais variados, sendo: sulcos, ravinas, escorregamentos, solapamentos de margem com consequentes desmoronamentos e inundações.

A aplicação da equação CP mostrou-se importante para o avanço dos conhecimentos sobre a cidade de Ponta Grossa, pois assim, deteve-se o número de processos ocorridos, onde houve a maior concentração dos mesmos, o que pôde ser relacionado com a evolução do uso da terra. No entanto, destaca-se que, essa equação e seus resultados devem ser bem entendidos, para que não hajam interpretações errôneas, pois em certos casos valores de CP altos podem ser resultantes de poucos processos ocorridos em áreas pequenas, o que não necessariamente indica o maior número de processos naquela área, ou seja, pode-se ter muitos processos ocorridos em uma classe com CP mais baixo.

O trabalho aqui realizado foi concluído considerando que as análises realizadas podem contribuir para o melhor conhecimento da dinâmica têmporoespacial da bacia do Arroio da Ronda, bem como, para compreender a sua influência nos processos geomorfológicos. Este trabalho, também pode ser uma contribuição para as tomadas de decisões sobre dinâmica espacial da bacia, considerando ações de gestão e planejamento urbanos e/ou regionais.

Destaca-se ainda que, apesar de finalizada, essa pesquisa corresponde a uma etapa ainda inicial dos conhecimentos acerca da bacia do Arroio da Ronda, sendo que a partir desta, demais estudos devem ser realizados, visando subsidiar ações de planejamento e gestão, bem como conhecer melhor os mecanismos que deflagram os processos geomorfológicos, como por exemplo, a realização de análises dos solos onde estes ocorrem, principalmente no que se refere aos pipe associados a colapsos.

CHRISTOFOLETTI, A. Geomorfologia. 2. ed. São Paulo: Edgard Blücher, 1980. 188 p.

GUERRA, A. J. T. Processos erosivos nas encostas. In: GUERRA, A. J. T.; CUNHA, S. B. da. Geomorfologia: uma atualização de bases e conceitos. Rio de Janeiro: Bertrand, 2001. p. 149-209.

GUERRA, A. T.; GUERRA, A. J. T. Dicionário GeológicoGeomorfológico. 6. ed. Rio de Janeiro: Bertrand Brasil, 2008. $652 \mathrm{p}$.

INSTITUTO BRASILEIRO DE GEOGRAFIA E ESTATÍSTICA - (IBGE). IBGE Cidades@. Disponível em: <www.ibge.gov. br.>.Acesso em: 16/06/2007. 
LÖWEN-SAHR, C. L. Estrutura interna e dinâmica social na cidade de Ponta Grossa. In: DITZEL, C. de H. M.; SAHAR, C. L. L. Espaço e Cultura: Ponta Grossa e os Campos Gerais. Ponta Grossa: Ed. UEPG, 2001. p. 13-36.

MEDEIROS, C. V. Processos erosivos no espaço urbano de Ponta Grossa - PR. 63 f. Monografia (Bacharelado em Geografia) - Setor de Ciências Exatas e Naturais, Universidade Estadual de Ponta Grossa, Ponta Grossa, 2000.

MELO, M. S.; GODOY, L. C. Geologia, geomorfologia e riscos geológicos na bacia do Arroio Olarias, Ponta Grossa, PR. Publicatio UEPG, Ponta Grossa, v. 3, n. 1, p. 33-59, 1997.

PONÇANO, W. L.; KERTZMAN, F. F.; SALOMÃO, F. X. T. Fatores geológicos, geomorfológicos e pedológicos no desenvolvimento de boçorocas na bacia do PeixeParanapanema (SP). Sociedade e Natureza, Uberlândia, v. 1, n. 2, p. 97-106, dez.1989.

PREFEITURA MUNICIPAL DE PONTA GROSSA (PMPG). Plano Diretor Participativo de Ponta Grossa, PMPG, 2006. Disponível em: <www.pontagrossa.pr.gov.br>. Acesso em: 27/09/2007.
RICCOMINI, C.; GIANNINI, P. C. F.; MANCINI, F. Rios e processos aluviais. In: TEIXEIRA, W.; TOLEDO, M. C. M. de; FAIRCHILD, T. R.; TAIOLI, F. (Orgs.). Decifrando a Terra. São Paulo: Oficina de Textos, 2001, p. 191-246. Cap. 10.

RIDENTE JR., J. L. Prevenção e controle da erosão urbana: bacia do Córrego do Limoeiro e bacia do Córrego do Cedro, Municípios de Presidente Prudente e Álvares Machado, SP. 115 f. Dissertação (Mestrado em Geociências) - Instituto de Geociências e Ciências Exatas, Universidade Estadual Paulista, Rio Claro, 2000.

SÁ, M. F. M. Os Solos dos Campos Gerais. In: MELO, M. S. de; MORO, R. S.; GUIMARÃES, G. B. Patrimônio Natural dos Campos Gerais. Ponta Grossa: Editora da UEPG, 2007. p. 73-83. Cap. 6.

SANTOS, M.; SILVEIRA, M. L. O Brasil: território e sociedade no início do século XXI. 8. ed. Rio de Janeiro: Record, 2004. $473 \mathrm{p}$.

TRICART, J. Ecodinâmica. Rio de Janeiro: SUPREN, 1977. $91 \mathrm{p}$. 
